\title{
Roles and Countermeasures of College Journals in College Education and Teaching
}

\author{
Shang Caijuan*, Wang Shengfeng, Niu Yanping, Shang Feifei, Wang Shuhui, Li Zengshan, \\ Luo Jing
}

Editorial Staff of Teaching and Research Support Center, Army Academy of Armored Forces, No.21

Dujiakan, Fengtai District, Beijing, China

*scj981@163.com

*Shang Caijuan

Keywords: college journals; education and teaching; countermeasure

\begin{abstract}
This paper summarizes the functions of college journals in college education and teaching, such as promoting the development of existing disciplines, supporting the construction of new disciplines, and training high-tech talents, and put forwards such specific countermeasures as carrying out the planning of selected topics, attaching significance to reviewing manuscripts, supporting and nurturing young authors, and improving overall qualities of editors.

College education and teaching is a complex system project and requires all aspects of cooperation and active cooperation. It is not something that a certain unit or a department can accomplish independently. It is difficult to get results in the short term. As a part of the school, the college journals have been playing an active role in discipline construction and talent training. The college journals are academic windows for the college. It can reflect the teaching and scientific research production, and the status of discipline construction and talent training. Based on this, this article summarizes the role of college journals in College education and teaching, and studies the specific countermeasures.
\end{abstract}

\section{Roles of College Journals in College Education and Teaching}

\subsection{Promoting the Development of Existing Disciplines}

Each college has some influential subjects at home and abroad. These superior disciplines are an important factor in improving visibility and reputation of the college. To a certain extent, it is the foundation of the college's establishment ${ }^{[1]}$. As a window for academic exchanges, the college journals provide good platform for the development of existing disciplines. It has the characteristics of a wide range of disciplines and rapid information dissemination. It is conducive to academic research of different disciplines on this platform, creating a keen academic atmosphere for the development of disciplines, and quickly deliver the latest research results of disciplines, especially key disciplines. It can demonstrate the academic strength and research level of the college and expand the influence of disciplines ${ }^{[2]}$.

\subsection{Supporting the development of new disciplines}

Based on the in-depth development of existing disciplines, and with the continuous deepening of scientific research, some researchers may have new scientific discoveries and gradually explore new areas of science, so as to resolve major issues that have not been solved by previous generations, and new disciplines are formed gradually. Compared with the existing superior disciplines and special disciplines, new disciplines are of low interest, late start of research, few researchers, and limited research levels. The research results may not be mature, easily controversial, not be accepted by people easily, and be difficult to develop. The college journals is a multi-disciplinary comprehensive academic journal. It advocates "let one hundred flowers blossom and one hundred schools of thought contend", and it is conducive to the academic discussion of 
different disciplines in this position ${ }^{[3]}$. The college journals can provide "fertile soil" for the construction of new disciplines, give full play to its own advantages, support the new disciplines in policy, and try to incline the new disciplines in the setting of columns, and it can be devoted to opening up columns, providing opportunities for researchers to publish the research results of the new disciplines, and priority for publication and rapid delivery. With the help of college journals, the new disciplines can attract the attention of peers and expand the influence of disciplines, so that the relevant college leaders have a certain degree of awareness and confidence in the development prospects of the new disciplines, attach importance to their construction and development, and urge them to make decision of increasing investment and active support, so that the new disciplines gradually cultivated as characteristic disciplines, and then gradually cultivated as superior disciplines ${ }^{[1]}$.

\subsection{Training High-tech Talents}

The basic task of the college is to train high-quality and high-tech talents. As the college journals, it mainly publishes the articles of the college's authors, and has close contact with teachers, scientific researchers, and students. It has the conditions to conduct face-to-face exchanges and guidance with the authors, and plays a role that no other social journal can play in discovering, supporting and training high-tech talents. The college journals are fertile ground for the growth of postgraduate students ${ }^{[4]}$. At present, postgraduate training programs all require that postgraduate students must publish a certain number of papers during their studies. Because college journals have adopted policy support for postgraduates, so that it becomes first choice of many postgraduate students to publish their papers. A considerable number of postgraduate students are still in the beginning stage of scientific research, their papers often have some immaturity. For such manuscripts, the editors of college journals often have to make repeated changes, so as to meet the publishing requirements. The editors will talk with the author about the scientific research topics he has done in face-to-face communication, find out the highlights and innovations of the manuscript, and help him to clarify the thinking and the structure.The college journals are also the base for training young teachers ${ }^{[4]}$. At present, among the educators and scientific research echelons, highly educated young teachers account for a large proportion. They are energetic and motivated, but most of them are still in the preliminary stage of teaching and scientific research, urgently need help and support. The college journals can provide them with a very good academic platform, and can quickly publish their new ideas and methods. They can improve their academic expression ability through face-to-face instruction and repeated revision of the papers by the journal editors. According to statistics, among the famous professors and well-known scholars in colleges, most of their first academic papers are published in college journals, and have embarked on the road to academic research from college journals ${ }^{[5]}$.

\section{Specific Countermeasures}

\subsection{Carrying Out the Planning of Selected Topics}

It is impossible for any college to make all disciplines develop at the same time. Therefore, it is necessary to allocate resources reasonably so that it cannot only promote the development of existing disciplines, but also support the development of new disciplines. Therefore, in the aspects of column planning and manuscript adoption, it should be consistent with the strategy on discipline construction and development. To promote the development of disciplines, college journals must strive to improve the quality. To improve the quality, journal editors should actively follow the scientific research projects of the key disciplines and special disciplines to understand their scientific research trends, and timely organize and submit manuscripts to project leaders or researchers for contributions. While guaranteeing the quality of internal manuscripts, the publication proportion of external manuscripts must also be increased. College journals must deliberately and voluntarily submit invitations to external authers, so as to introduce the latest research results of external disciplines, and drives the construction and development of internal 
disciplines with high-quality academic level ${ }^{[2]}$. For the new disciplines, the college journals should give some support to the policy, set columns for it, and organize and submit manuscripts.

\subsection{Attaching significance to reviewing manuscripts}

In the era of rapid development of modern information, the timeliness of the publication of scientific research results is very important. If college journals want to attract more authors, it must attach significance to review manuscripts and improve the reviewing efficiency. Good research results are published timely to promote the transformation of results and the advancement of disciplines. The preliminary review of editors should be fast. For manuscripts that have no research value, they should explain why. For manuscripts with research value but problems with writing standards, the editors should guide patiently, explain the writing requirements and standards to the authors. After the preliminary review, it is necessary to choose experts cautiously, and the review results by experts is the key to ensuring the quality of manuscripts. Choosing the right reviewing experts, editors can not only obtain high-quality review opinions, but also understand the advantages and weaknesses of manuscripts, and provide scientific basis for editing manuscripts for follow-up processing, and also improve the editorial efficiency. After receiving comments from experts, editors should revise the articles as soon as possible and give feedback to the authors in time. The editors should point out the problems in the content, structure, and writing of manuscripts, so that authors can focus on the changes, and improve writing level through the revision process, and lay foundation for future research work.

\subsection{Supporting and Nurturing Young Authors}

Young authors are the main parts of college journals, and they are also the reserve forces for the construction and development of disciplines. Journal editors should pay attention to their cultivation and fully mobilize their enthusiasm for scientific research. The journal editors must have a good sense of service, be enthusiastic about them, encourge, support and cultivate them as much as possible, so that they can quickly become the backbone of college education and teaching. In addition, if their manuscripts are not accepted, the editors should do a good job in returning the manuscripts, such as submit the review comments of manuscripts to the author in detail, patiently indicate that the reasons, point out how to improve manuscripts so as to meet publishing requirements, identify topics and provide writing ideas for them as much as possible. College journals should protect young authors' enthusiasm, boost their growth, and actively nurture reserve forces for the development of disciplines and the construction of journal authors ${ }^{[1]}$.

\subsection{Improving Overall Qualities of Editors}

The editorial work is the central link of college journals' publishing work. To produce high-quality and influential college journals, it is necessary to focus on improving overall qualities of editors. Journal editors must tolerate loneliness, indifferent to fame and fortune, have a high sense of responsibility and enterprise, and have the dedication of "willing to do for others" and the collaborative spirit of teamwork. They must have a sense of learning and make an effort to be scholarly editors. They must have profound professional knowledge and be experts in certain field, keep up with the development of disciplines, understand the latest developments, so as to improve the identification, judgment and compilation of manuscripts in this field. They have extensive scientific knowledge, involve in many different fields, understand the development frontiers of various disciplines, tracks the growing points of disciplines, and discover high-level authors. They must have a sense of innovation, be able to be sensitive to dynamic frontiers of disciplines, be good at capturing new information emerging in the development of science and technology. They must have the courage to create and innovate in the selection of topics and setting of columns, so as to improve social influence of college journals through creative planning and promote the development of disciplines. They must have good professional qualities, such as dedication, responsibility, fairness and justice, and good service awareness, help authors to lay foundation for future growth and progress on the scientific research road. 


\section{References}

[1] Liu, M. S. Role of University Journals of Natural Science in Disciplinary Construction and Development[J]. Acta Editologica, 2012, 24(3): 210-213.

[2] Liu, Y. and Liu, X. J. On the Role of College Journals in the Construction of Disciplines and Ways to Promote the Development of Disciplines [J]. Chinese Journal of Scientific and Technical Periodicals, 2012, 23(2): 297-300.

[3] Shen, J. Z., Chen, H. and Gao S. J. The Role of University Journals in the Construction of Disciplines[J]. Acta Editologica, 2000, 12(1): 43-44.

[4] Lu, S. Z. Give Full Play to the Role of College Journals in Discipline Construction [J]. Journal of Changchun University of Technology (Higher Education Study Edition), 2006, 27(1): 119-120.

[5] Xiu, R. R. and Liu, W. Q. The Role of Journals in the Discipline Construction of Colleges and Universities [J]. Journal of Shandong University of Technology (Social Sciences), 2011, 27(2): 84-87. 